\title{
Designing with Building Bricks and Shape Grammar
}

\author{
Frederico Braida \\ Graduate Program in Built Environment, Federal University of Juiz de Fora, Juiz de Fora 36036-900, Brazil
}

\begin{abstract}
This paper correlates the use of building blocks with the shape grammar theory in the design process. The main goal is to present the potentialities of the various building blocks, which combined with Shape grammar can contribute to the creative process, particularly for the formal composition in the field of Architecture, Urbanism and Design. The methodology is based on a literature review and reflections derived from the observations of the use of the building blocks during experiments carried out in the scope of research with students of the undergraduate course in Architecture and Urbanism. Starting from the discussions proposed by George Stiny on design with Froebel's buildings gifts and from experiments with other building blocks, such as Archbricks, it is found that building blocks have their own vocabulary and rules, which can be appropriated and exploited by designers in the construction of new shape grammars.
\end{abstract}

Key words: Shape grammar, building bricks, design, architecture.

\section{Introduction}

In the design process, one of the stages in which designers - be they students or professionals - present greater difficulties is in the formal conception. Some theories and methodologies can help designers in this task. Shape grammar is one of those methodologies and formalist theories that can contribute to the design process.

In this paper we present the building bricks (or building blocks) as objects that can aid the shape grammar-backed design process. The main issue addressed in this paper is: how can building bricks contribute to the design process and how can they be used in the shape grammar methodology?

The issues discussed in this paper are the result of a research developed at the Laboratory for the Study of Languages and Expressions of Architecture, Urbanism and Design (LEAUD), linked to Design, Representation and Technology Department from the Faculty of Architecture and Urbanism and to Graduate Program of Built Environment of Federal University of Juiz de Fora (UFJF), Brazil. The research, since 2014,

Corresponding author: Frederico Braida, architect and urbanist, PhD in design, research fields: graphic representation, graphic education, design, digital design and contemporary architecture. has been funded by both the State of Minas Gerais Research Foundation (FAPEMIG) and the UFJF, and was attended by several undergraduate and graduate students.

The methodology is based on a literature review and reflections derived from the observations of the use of the building bricks during the experiments carried out in the scope of the research.

The main aim of this paper is to present the potential of the building bricks in the design process, mainly when considering shape grammar.

\section{The Shape Grammar Theory}

The shape grammar can be considered as a formalistic method for the generation and analysis of geometric compositions. Shape grammar is embedded in the area of knowledge named Computational Design, which aims to incorporate computing-logical and mathematical thinking-into creative processes [1].

The shape grammar theory was developed in the early 1970s by George Stiny and James Gips. It was conceived from the production system of mathematicians Emil Post and Alan Turing and from the studies of the linguist Noam Chomsky [2, 3].

Since the 1950s, Chomsky and other linguists at the 
Massachusetts Institute of Technology (MIT) have proposed generative grammar. According to these linguists, with a limited number of grammatical rules and a finite set of words, one can generate an infinite number of sentences.

It was from these concepts that Stiny and Gips [4] proposed a rules-based form generation system for artistic compositions, paintings and sculptures. The idea was to design a set of initial forms and some combination rules. From these elements, numerous final compositions could be generated. Thus, instead of working with words, Stiny and Gips proposed a grammar for geometric forms.

For the proposition of a shape grammar, one must first establish a vocabulary of forms, which can be two- or three-dimensional, composed of points, lines, planes and solids. Next, the spatial relations between the primitive forms must be established. Then, the transformation rules must be defined, which can vary amongst addition, subtraction or substitution operations [5]. Some other transformations can also be translation, rotation, mirroring, roto-translation and scale transformation. Finally, derivations are made, the applications of the rules through which the final composition will be reached.

There are several shape grammars already developed as variations of the original one. Some of them are: analytical form grammar, discursive grammar, parametric shape grammar, set grammar, grammar with labels and color grammar. All these types of grammar can be used as a methodology of analysis, aiming at deciphering the rules underlying a given formal language, or as a synthesis methodology, with the purpose of generating a set of solutions from pre-established forms and rules $[6,7]$. These are the various types of shape grammar that have been used in Architecture, Urbanism and Design.

\section{Shape Grammar in Architecture, Urbanism and Design}

In the field of Architecture, Urbanism and Design, the studies of the shape grammar have gained a great repercussion, still today. All around the world we find researches that approach the topic of shape grammar, mainly implementing this theory in computer programs, as in parametric modeling software.

Mohamed [8] highlights, among other researchers, besides the creators, the names of William Mitchell and Terry Knight as important researchers of shape grammar in the field of Architecture and Urbanism. Also deserve to be mentioned, in the Iberoamerican context, José Pinto Duarte and Gabriela Celani. These researchers, their mentees and many other researchers have developed several studies in which the shape grammar is used for generations of new forms as well as for the analysis of projects of different architects for the deciphering of architectural languages.

Although shape grammar had been created for formal composition in the arts, in the late 1970s and early 1980s Stiny and Mitchell developed studies of the "Palladian villas" and the Taj Mahal gardens, verifying the possibilities of applying the shape grammar in Architecture. From then on, the grammar shape was adopted as methodology for the study of the language of specific architects, architectural styles or urban morphology.

\section{Materials and Methods}

This paper is a product from both literature review and empirical research about the use of building bricks in the scope of formal conception of architectural design in an academic context.

Nowadays, the bibliography on the shape grammar is already quite enlarged and it is possible to find papers published in proceedings and in scientific journals, post-graduate theses and books. The site $\mathrm{http}: / / w w w . s h a p e g r a m m a r . o r g /$ contains an important collection of bibliographies, with several texts about the beginnings of the thinking about the shape grammar and its applications, as well as some original papers of Stiny and Gips.

The researches developed in LEAUD using building 
bricks have contemplated a diversity of blocks sets, which are constituted by different formal vocabularies, different materials (woods and plastics), varied colors (monochrome or colored) and multiple rules of combination (juxtapositions and overlaps, fittings and joints with magnets). The different games are capable of generating different shape grammars.

In addition to some building bricks, such as $L E G O$ Architecture Studio, Playmags, Tegu and Plus-Plus, we have also used the Archbricks, which were developed by LEAUD as a result of research on the building blocks as didactic material for the formal design.

It is from the use of these blocks sets that we can think of the contribution of the games to the Architecture, Urbanism and Design project associated with the shape grammar theory.

\section{The Building Bricks and Shape Grammar}

In 1980, Stiny published a paper in which he used Froebel's building gifts in the study of Kindergarten grammars. At that time, the potential of building bricks was revealed in the application of studies involving shape grammar.

As is known, Froebel's gifts continue to be used to this day as material for early childhood education. These blocks explore three formal categories: forms of knowledge (arithmetical and geometrical facts), forms of life (e.g., furniture and buildings) and forms of beauty (symmetrical patterns). Stiny, in the paper mentioned above, stated that using the Froebel's gifts "the child learns to solve his design problems with the gifts and his discourses for himself their properties and possibilities for design" [9].

The Froebel's gifts, the forerunners of all building bricks, have also influenced a number of architects, including Frank Lloyd Wright. Also Le Corbusier and Buckminster Fuller, among other renowned architects, were influenced by the use of building bricks [10]. Including, there are some building bricks designed by architects. An example is Wright Blocks, created by
John Lloyd Wright, a nephew of Frank Lloyd Wright and inventor of Lincoln Logs (another building blocks set made of wood).

These building bricks designed as primary wood solids, when combined, enable a wide variety of compositions. That is why they were also used by Stiny. "Each combination of a vocabulary and a system of categories may thus be considered to establish a language of designs", so the Kindergarten method can be viewed as a way to teach such languages [9].

Stiny [9] also mentions some other games that can be used in design exercises using the shape grammar: Bauhaus blocks designed by Alma Buscher, Lowenfeld's Poleidoblocs and Abbatt's building bricks. These three wood building blocks can be added others that are for sale, especially in children's toy stores. For example, in our research, we have used Jenga, Multiblocks and Playing of Engineer (Brincando de Engenheiro in Portuguese).

Jenga is the one which has only one form: a monochromatic parallelepiped. Multiblocks feature a variety of parts, including cylinders and triangular base prisms. The pieces are dyed in the colors green, red, yellow and blue. Finally, Playing of Engineer has pieces that refer to the construction of castles or factories, as it has pieces that resemble bridges and towers built with brick.

Also we have used in our research the Montessori Golden Bead Material or the Dienes blocks - the base ten blocks, also known as the Multibase Arithmetic Blocks (MAB) —as formal vocabulary for the architectural project. Although created for mathematical studies, they can be used as formal vocabulary for the development of a shape grammar. In addition to the building blocks made of wood, the LEGO bricks game should be highlighted nowadays. The main difference between the $L E G O$ and the other games mentioned is that the first is made of plastic and has some tubes that allow a lot of building possibilities. It should be noted that the possibilities of assembling already work as rules underlying the game itself, which 
can be taken into account when the shape grammar rules are established. There are pieces that can only be fitted together. Other parts also allow lateral fittings.

Other examples of building blocks that have an interlocking principal are Build Everything (Monta Tudo in Portuguese) and Elka Magic Pins. Arckit can also be considered a building blocks set, although it is specifically geared to the field of Architecture, with very specific assembling rules. Archbricks, manufactured with a $3 \mathrm{D}$ printer, is also a building blocks set made of plastic that has some holes and pins for assembling.

Finally, it is worth mentioning the building blocks that can be assembled by means of magnet. This type of building blocks is very versatile. Some examples are Playmags and Tegu. Tegu's formal vocabulary approaches logical blocks with more basic forms, while the Playmags blocks feature a wide range of formal variety.

As you can see, we currently have a series of toys and games which can be used in the processes involving the shape grammar. All these building bricks, somehow, refer to the traditional Froebel's gifts and compose different grammars and languages, as they are formed by different vocabularies. According to Stiny, "of course, by changing the vocabulary or the system of categories, different languages of designs could be established" [9].

\section{Designing with Building Bricks and Shape Grammar}

Transported from the universe of Kindergarten and children's games and toys to design studios, the building bricks serve to conceive architectural languages. "The pieces of the building gifts may be viewed as simple architectural elements, and thereby provide a rich source of material for architectural composition" [9].

Using building bricks, from simple regulation sequences it is possible to develop complex forms. Thus, the project resulting from the use of building blocks and shape grammar is not a result of chance but rather of the application of rules predetermined by the designer in accordance with the rules intrinsic to the building bricks used, within a formal vocabulary of their own. For example, Archbricks parts have forms and fittings that allow addition and subtraction operations (Fig. 1). Even with a restricted formal vocabulary, in applying some rules, it is possible to develop a wide variety of forms.

According to Mitchell, "formally we can say that designing is to perform a logical-mathematical procedure in an algebra of forms to produce the necessary information on these forms, and that the rules of a shape grammar specify how to perform this procedure" [11].

Building blocks constitute volumetric design worlds. "A design world provides graphic symbols (forms) that represent architectural elements. The rules of a grammar specify how these symbols can be handled. A design process is a logical procedure performed with specified predicates, according to these rules; in other words, is a sequence of operations on graphic symbols performed with the purpose of satisfying the predicates

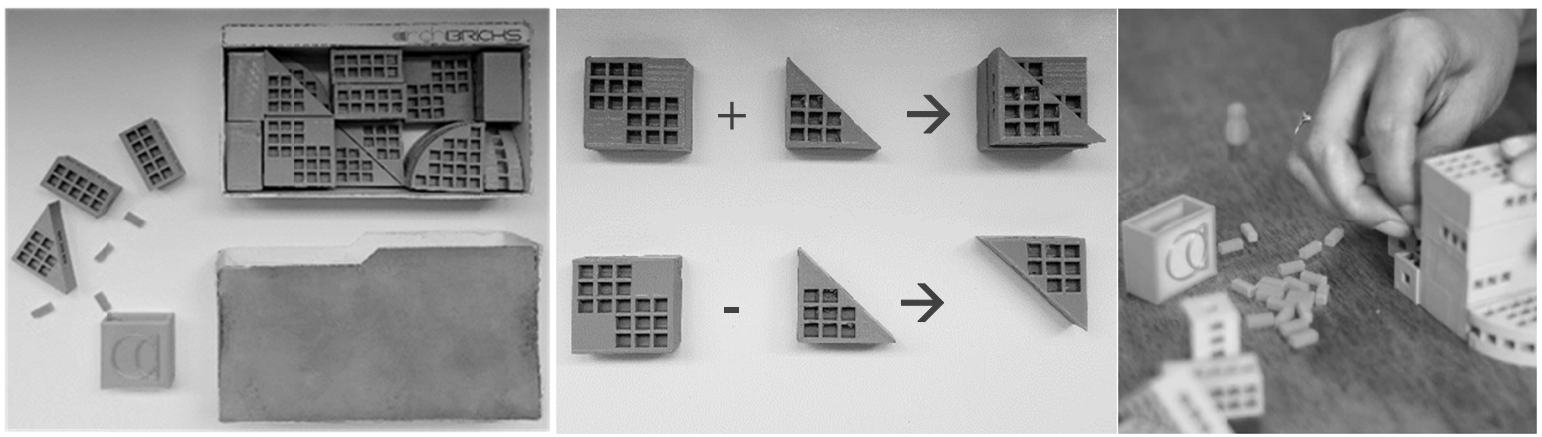

Fig. 1 Designing with Archbricks building bricks. 
specified for this design world" [11].

With the shape grammar it is possible to create families of objects, which have formal relations with each other. That is why, in a way, the logic of the design developed with building bricks also reaches out for the thinking of modular design.

\section{Discussion}

It is interesting to note how building bricks can be used in design teaching, particularly in the exploration of generative shape grammar. Thus, it can be associated the benefits of designing using the building bricks with the benefits of the shape grammar methodology.

On the one hand, it can be pointed out as positive aspects of the use of building bricks: the use of this material provides a ludic experience in which the designer can design playing, going back to the ludic way of learning as a child. The amusement provided by the building blocks encourages creativity, since it removes the designers from a pressure environment, especially in front of the blank sheet. Finally, building bricks are concrete, three-dimensional, palpable materials. Similar to any set of logical blocks, the building blocks help designers to exercise abstraction and they function as a mean of representing the form. The quick and easy manipulation of building bricks allows you to assemble different three-dimensional models during the design phase.

On the other hand, the shape grammar offers the support for a logical and mathematical (computational) reasoning applied to the design. With the grammar shape, from an initial formal vocabulary chosen by the designer himself and a set of rules, numerous alternatives are generated, among which the designer can select the one that suits him best. Thus, we agree with Stiny, when stating that "using rules instead of intuition, the designer needs no longer rely on 'creative inspiration', the 'inventive flash', or 'individual genius"” [9].
It should be noted that the assembling games already have a vocabulary of forms and rules of fitting previously given. Therefore, its application with the grammar shape is coherent. The building blocks have different rules intrinsic to them, which can be incorporated or even subverted during the design process, at the time of describing the rules of shape grammar.

Through all these aspects, there are several possibilities of application of building bricks in architectural design process.

\section{Conclusion}

The possibilities of use of the building blocks sets in the design process are innumerable. What was sought in this paper was to highlight the possibilities in the context of the application of the shape grammar.

Although Stiny had already revealed the contributions of the use of Froebel's gift for the application of the shape grammar, in addition to other researchers have used off-cuts of wood specifically made to compose a formal vocabulary, this paper has tried to emphasize that other toys and games can be used, mainly because they already carried, within themselves, an initial formal vocabulary and the rules of possible spatial relations.

Therefore, building bricks associated with shape grammar present themselves as a powerful design methodology capable of being used in many different types of Architecture, Urbanism and Design, whether in professional or academic context. With these elements are joined the ludic aspects and the logical reasoning required in the processes of formal composition.

\section{Acknowledgments}

This research was supported by Fundação de Amparo à Pesquisa do Estado de Minas Gerais (FAPEMIG Fundation)—Processes TEC APQ 01041/14 and TEC PPM 00766/15. 


\section{References}

[1] Celani, G. 2008. "Preface to the Brazilian Edition." In The Logic of Architecture: Design, Computing and Cognition, edited by Mitchell, W. J. Campinas: Unicamp.

[2] Paio, A. 2016. "Shape Grammar." In 101 Concepts of Architecture and Urbanism in the Digital Age, edited by Braida, F., et al. São Paulo: ProBooks, 114-5.

[3] Celani, G., et al. 2006. "The Shape Grammar as Methodology of Analysis and Synthesis in Architecture." Connection-Communication and Culture, UCS 5 (Caxias do Sul.): 10.

[4] Stiny, G., and Gips, J. 1972. "Shape Grammars and the Generative Specification of Painting and Sculpture." In Proceedings of 7 IFIP Congress. Amsterdam: Freimanp, 1460-5.

[5] Stiny, G. 2006. Shape: Talking about Seeing and Doing. Cambridge: MIT Press.
[6] Knight, T. W. 1991. "Designing with Grammars". In Proceedings CAAD Futures Digital, 33-48.

[7] Pupo, R., Pinheiro, E., Mendes, G., Kowaltowski, D., and Celani, G. 2007. "A Design Teaching Method Using Shape Grammars." In Proceedings of 7 Graphica, UFPR, Curitiba.

[8] Mohamed, S. M. 2005. Creative Approach to Design Formulation Shape Grammars as a Tool in Architecture Design Analysis and Synthesis. Department of Architecture, Faculty of Engineering, Alexandria University.

[9] Stiny, G. 1980. "Kindergarten Grammars: Designing with Froebel's Buildings Gifts.” Environment and Planning B 7: 409-62.

[10] Turner, C. 2014. LEGO Architecture Studio: Create Your Own Architecture. Denmark: The LEGO Group.

[11] Mitchell, W. J. 2008. The Logic of Architecture: Design, Computing and Cognition. Campinas: Unicamp. 